\title{
MIEDO Y ANSIEDAD ANTE LA MUERTE EN EL CONTEXTO DE LA PANDEMIA DE LA COVID-19
}

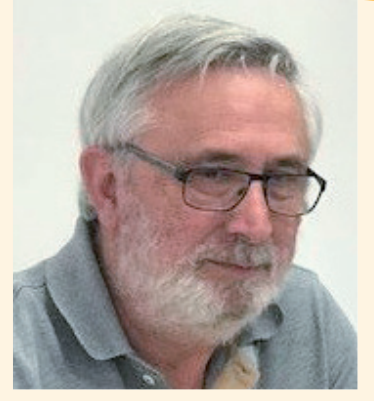

JOAQUÍN TOMÁS-SÁBADO

Escoles Universitàries Gimbernat, adscritas a la Universitat Autònoma de Barcelona. Sant Cugat del Vallès (Barcelona).
La propagación de epidemias que han provocado una alta mortalidad en la población no es un fenómeno nuevo y ha sucedido desde el inicio de la civilización. La peste, el cólera o el tifus, por ejemplo, eran de aparición recurrente en épocas pasadas, con consecuencias realmente devastadoras.

En tiempos más modernos, la pandemia de la llamada «gripe española» de 1918 acabó con la vida en un solo año de, al menos, 50 millones de personas, incluyendo una alta mortalidad infantil ${ }^{1}$. Según parece, la enfermedad desapareció, básicamente, cuando la gran mayoría de los supervivientes estuvieron inmunizados. El síndrome de inmunodeficiencia adquirida (sida), otra gran pandemia de la segunda mitad del siglo $x x$, se estima que ha causado la muerte de unos 35 millones de personas en todo el mundo, además de provocar importantes cambios en las

Correspondencia: Joaquín Tomás-Sábado Correo electrónico: joaquin.tomas@eug.es formas de la atención sanitaria y las relaciones sociales.

Los 20 años transcurridos del siglo actual también han sido pródigos en epidemias y alarmas sanitarias globales. En 2014, aparece un brote importante de infección por el virus del Ébola y, en 2015, se produce la propagación del virus del Zika, sin olvidar otras amenazas, como la gripe aviar, la gripe porcina o el síndrome respiratorio agudo grave (SARS; por las siglas en inglés de: severe acute respiratory syndrome).

El 31 de diciembre de 2019, la Organización Mundial de la Salud (OMS) informa de la aparición en Wuhan, China, de una neumonía viral causada por un nuevo coronavirus (SARS-CoV-2)². A partir del 23 de marzo, la enfermedad por el coronavirus de 2019 (COVID-19; por las siglas en inglés de: coronavirus disease 2019) adquiere características pandémicas y se 
extiende rápidamente por todo el mundo, infectando a cerca de siete millones de personas, de las que han fallecido más de 400000 (datos del 8 de junio de 2020) y provocando cambios rápidos y sin precedentes en la vida diaria y en las relaciones sociales, en un intento desesperado por contener los contagios.

Se sabe que existen vínculos claros entre alarmas sanitarias y síntomas elevados de estrés, ansiedad y tendencias suicidas ${ }^{3}$. La pandemia actual constituye una amenaza de muerte directa y, como tal, supone la aparición de una respuesta con una serie de síntomas psicológicos. Estudios muy recientes ${ }^{4,5}$ han encontrado un aumento alarmante de trastorno de estrés postraumático, depresión, ansiedad generalizada e insomnio en el personal sanitario expuesto al coronavirus. En la población general, también se evidencia un incremento de los cuadros de depresión, ansiedad, estrés y problemas para dormir desde que se declaró la pandemia.

\section{MIEDO Y ANSIEDAD ANTE LA MUERTE}

La muerte, por lo general, presenta connotaciones muy negativas, ya que suele asociarse a la tristeza, el dolor, la pérdida y el final. Por otro lado, tampoco es un tema del que sea fácil hablar, ya que supone referirse a la separación y al sufrimiento, de manera que se tiende a ocultar y medicalizar, prefiriendo que sea rápida y repentina y que ocurra cuando uno está dormido, sin ninguna o casi ninguna consciencia ${ }^{6}$.

Aunque la muerte constituye un elemento universal e inseparable de cualquier forma de vida, adquiere una dimensión singular en el ser humano, en el que genera una amplia gama de actitudes y emociones de diversa intensidad cuando toma consciencia de la evidencia de su propia mortalidad, de su finitud, destacando la ansiedad, el miedo y la depresión. De alguna manera, estas emociones constituyen la manifestación del instinto de supervivencia más primario y, evidentemente, contribuyen decisivamente a prolongar la vida. Sin embargo, cuando no se dispone de las defensas adecuadas, pueden ser una importante causa de angustia y desajuste emocional ${ }^{7}$.

Desde esta perspectiva, la pandemia de la COVID-19, percibida como una amenaza real a la vida, ha activado todos nuestros miedos existenciales. La evidencia de la inevitable mortalidad es aterradora e intolerable y todo aquello que nos recuerde a la enfermedad y la muerte despierta nuestros temores reprimidos más íntimos y provoca reacciones de desesperación y te- mor, constituyendo la causa primaria y fundamental de la ansiedad experimentada por las personas ${ }^{8}$.

De forma general, la ansiedad constituye un estado de tensión anticipatoria que aparece ante la percepción de una amenaza de peligro inminente, que tiene su origen en un elemento desconocido o indeterminado, y se manifiesta por intranquilidad, inquietud e inseguridad.

La ansiedad y el miedo constituyen estados negativos muy relacionados, que, en ocasiones, pueden confundirse. Ambos comportan la vivencia molesta de intranquilidad y tensión, pero existen diferencias entre ambas situaciones, cuya consideración permite distinguir entre ellas. El miedo tiene un enfoque específico, es episódico y disminuye o desaparece cuando el peligro se aleja de la persona, o la persona del peligro. Por el contrario, en la ansiedad, es difícil identificar la causa de la tensión y de la intranquilidad o la naturaleza del suceso anticipado; sería como tener miedo a algo, sin saber exactamente qué es ese algo . En la tabla 1 , figuran los principales aspectos deferenciales entre miedo y ansiedad, aplicables tanto al miedo $y$ ansiedad en general, como a los relacionados con la muerte.

\section{La pandemia de la COVID-19, percibida como una amenaza real a la vida, ha activado todos nuestros miedos existenciales.}




\begin{tabular}{|l|l|}
\hline \multicolumn{2}{|c|}{ Tabla 1. Aspectos diferenciales entre miedo y ansiedad } \\
\hline Miedo & Ansiedad \\
\hline Conexión comprensible entre el peligro y el miedo & Conexión indeterminada entre el peligro y la ansiedad \\
\hline Suele ser de duración breve & Prolongada \\
\hline Peligro identificable & Peligro desconocido \\
\hline Disminuye cuando se aleja el peligro & Persistente \\
\hline Respuesta a peligro inminente & No suele existir peligro inminente \\
\hline Sensación de emergencia & Estado de hipervigilancia \\
\hline Circunscrito a un área específica & Sin límites claros \\
\hline
\end{tabular}

Según esto, la ansiedad ante la muerte constituye una reacción emocional producida por la percepción de señales de peligro o amenaza, reales o imaginados, a la propia existencia, que pueden desencadenarse ante estímulos ambientales como cadáveres, cementerios, etc.; estímulos situacionales que se hayan condicionado por asociación con los anteriores y sean capaces de provocar una respuesta condicionada; y también por estímulos internos de la persona, como pensamientos o evocación de imágenes relacionadas con la muerte propia o ajena ${ }^{9}$.

Para Lonetto y Templer ${ }^{10}$, la ansiedad ante la muerte tiene dos determinantes fundamentales: el estado de salud psicológica y las experiencias personales relacionadas con la muerte. Posteriormente, añaden un tercer factor, de tipo existencial, que estaría relacionado con la idea de cómo encaja uno en el mundo y el significado que se atribuye a la vida y la muerte. Puede estar condicionada tanto por generadores internos como externos. Los generadores internos ( $p$. ej., pensamientos sobre la muerte) estarían relacionados con componentes obsesivos, mientras que los generadores externos (cementerios, ataúdes, etc.) estarían más asociados a componentes fóbicos.

Aunque, en ocasiones, las expresiones «miedo a la muerte» $y$ «ansiedad ante la muerte» se uti-

\section{Las actitudes proactivas y optimistas con respecto al futuro pueden ayudar a mantener un relativo equilibro de la salud mental en estos tiempos de incertidumbre.}

lizan de forma sinónima, como sucede en el caso de la ansiedad y el miedo a nivel general, también aquí existen una serie de características que las diferencian. Ya sabemos que el término miedo se aplica, de manera estricta, para describir la reacción emocional que se experimenta ante un peligro específico, una amenaza identificable. Por el contrario, en el estado ansioso, el individuo tiene dificultades para identificar la causa de la tensión y la intranquilidad. Según esto, parece inadecuado hablar de miedo a la muerte cuando nadie sabe exactamente qué es estar muerto. Las personas pueden experimentar miedo respecto a algunos aspectos específicos de la muerte, como sus causas, el dolor o el propio proceso de morir, pero la experiencia de estar realmente muerto es desconocida y, por lo tanto, las reacciones de aprensión o inquietud hacia ella 
deben ser considerados como ansiedad $^{11}$.

El grado de ansiedad ante la muerte varía entre los individuos y puede aumentar o disminuir en función de los eventos vitales. Algunas circunstancias negativas, como la pérdida del trabajo, los accidentes, la mala salud o la pérdida de seres queridos son recordatorios de la muerte y pueden despertar los sentimientos reprimidos de temor. Está comprobado que tanto las catástrofes naturales como las provocadas por el hombre contribuyen especialmente a activar la ansiedad ante la muerte.

\section{LA PANDEMIA Y LA SALUD MENTAL}

La COVID-19 ha impuesto muchos cambios en la vida de las personas. El distanciamiento físico necesario para frenar la transmisión del virus ha alterado seriamente las redes sociales, aumentando el aislamiento social, un conocido factor de riesgo de depresión y conducta suicida. Asimismo, ha provocado, entre otras consecuencias, la alteración de las rutinas diarias, un aumento de las dificultades financieras, la sobrecarga de información y la incertidumbre sobre el futuro.

Los esfuerzos para afrontar la pandemia se han centrado principalmente en el control de los contagios, las tasas de curación y la búsqueda de una vacuna efectiva, sin que las previsibles consecuen- cias sobre los aspectos psicosociales y la salud mental se hayan considerado aún a fondo ${ }^{12}$.

Aunque los sentimientos de miedo, ansiedad, tristeza e incertidumbre son normales en una situación de pandemia, donde se desconoce cuáles serán sus consecuencias reales, lo cierto es que constituye un desafío emocional para todos, especialmente, para aquellas personas que ya están en riesgo por presentar cuadros de ansiedad o depresión ${ }^{13}$, en las que puede producirse un aumento de la ideación y las conductas suicidas $^{14}$.

En Estados Unidos, se ha detectado que, desde febrero de 2020, a medida que se imponían las medidas para contener la propagación de la enfermedad, se disparaba la venta de armas de fuego, con un aumento del $85 \%$ en el mes de marzo, comparado con el mismo mes de 201915. Teniendo en cuenta la conocida relación que existe entre la posesión de armas de fuego y la conducta suicida, los expertos temen que la combinación de la crisis económica y social provocada por la COVID-19 y el aumento de la venta de armas pueda desencadenar una oleada de suicidios.

Los medios de comunicación pueden ejercer una importante función en la difusión de información útil para la población, aunque su exposición excesiva puede actuar como un activador de las respuestas ansiosas y depresivas. La constante información y comentarios referidos al número de contagios y fallecidos pueden Ilevar también a sobreestimar los riesgos reales de contraer la enfermedad.

Aunque el control de las emociones negativas puede ser difícil en esta situación, hay que considerar que, afortunadamente, la gran mayoría de las pandemias que ha padecido la humanidad desaparecieron casi tan rápidamente como comenzaron. A día de hoy, es aventurado hacer predicciones sobre el futuro próximo, sobre cómo será la vida social y las relaciones en la «nueva normalidad». No obstante, las actitudes proactivas y optimistas con respecto al futuro pueden ayudar a mantener un relativo equilibro de la salud mental en estos tiempos de incertidumbre.

\section{BIBLIOGRAFÍA}

1. Taubenberger JK, Morens DM. The 1918 influenza pandemic and its legacy. Cold Spring Harb Perspect Med. 2019;a038695.

2. Whitworth J. COVID-19: a fast evolving pandemic. Trans R Soc Trop Med Hyg. 2020;114(4):241-8.

3. Wheaton MG, Abramowitz JS, Berman NC, Fabricant LE, Olatunji BO. Psychological predictors of anxiety in response to the H1N1 (swine flu) pandemic. Cognit Ther Res. 2012; 36(3):210-8.

4. Lee SA. Coronavirus anxiety scale: a brief mental health screener for COVID-19 related anxiety. Death Stud. 2020;44(7):393-401.

5. Liu S, Yang L, Zhang C, Xiang YT, Liu Z, Hu S, et al. Online mental health services in China during the 
COVID-19 outbreak. Lancet Psychiatry. 2020;7(4):e17-e18.

6. Limonero JT. Ansiedad ante la muerte. Ansiedad Estrés. 1997; 3(1):37-46

7. Tomás-Sábado J. Miedo y ansiedad ante la muerte. Aproximación conceptual, factores relacionados e instrumentos de evaluación. Barcelona: Herder; 2016.

8. Limonero JT. El fenómeno de la muerte en la investigación de las emociones. Rev Psicol Gral Aplic. 1996;49(2):249-65.

9. Tomás-Sábado J, Fernández-Narváez P, Fernández-Donaire L,
Aradilla-Herrero A. Revisión de la etiqueta diagnóstica ansiedad ante la muerte. Enf Clín. 2007;17(3): 152-6.

10. Lonetto R, Templer DI. Death anxiety. Washington D.C.: Hemisphere Publishing; 1986.

11. Kastenbaum R. The psychology of death. Nueva York: The Guilfort Press; 1992.

12. Ahorsu DK, Lin CY, Imani V, Saffari M, Griffiths MD, Pakpour AH. The Fear of COVID-19 Scale: development and initial validation. Int J Ment Health Addict. 2020;1-9. [En prensa].
13. Klomek AB. Suicide prevention during the COVID-19 outbreak. Lancet Psychiatry. 2020;7(5):390.

14. Brooks SK, Webster RK, Smith LE, Woodland L, Wessely S, Greenberg $\mathrm{N}$, et al. The psychological impact of quarantine and how to reduce it: rapid review of the evidence. Lancet. 2020;395(10227):912-20.

15. Mannix R, Lee LK, Fleegler EW. Coronavirus disease 2019 (COVID-19) and firearms in the United States: will an epidemic of suicide follow? Ann Intern Med. 2020. [En prensa]. 